\title{
MINERAL DUST IMPACT ON SHORT- AND LONG-WAVE RADIATION AND COMPARISON WITH CERES MEASUREMENTS
}

\author{
Salvatore Romano*, Maria Rita Perrone \\ Department of Mathematics and Physics, Università del Salento, Lecce, 73100, Italy \\ *Email: salvatore.romano@unisalento.it
}

\begin{abstract}
Clear-sky downward and upward radiative flux measurements both in the short- and in the longwave spectral range have been used to estimate and analyze the radiation changes at the surface due to the mineral dust advection at a Central Mediterranean site. Then, short- and long-wave radiative fluxes retrieved from the CERES (Clouds and the Earth's Radiant Energy System) radiometer sensors operating on board the EOS (Earth Observing System) AQUA and TERRA platforms have been used to evaluate the mineral dust radiative impact at the top of the atmosphere. Satellite-derived radiative fluxes at the surface have been compared with corresponding groundbased flux measurements, collocated in space and time, to better support and understand the desert dust radiative impact. Results referring to the year 2012 are reported.
\end{abstract}

\section{INTRODUCTION}

Mineral dust aerosols play an important role in the Earth's radiation budget influencing significantly the climate system through direct (scattering and absorption of solar and terrestrial radiation) and indirect effects (acting as cloud and ice nuclei of condensation). In a more detail, mineral aerosols cause the decrease of the incoming short-wave (SW) radiation at the surface (cooling effect) as a consequence of their scattering and absorption properties. Conversely, they enhance the greenhouse effect in the long-wave (LW) spectral range by trapping the outgoing terrestrial radiation at the surface (warming effect). The Mediterranean basin represents one of the most important areas for the study of the mineral aerosol impacts due to its proximity to the Sahara desert. Mineral dust outbreaks affect the Mediterranean area mostly in summer and contribute to one of the highest radiative effects in the world [1].
The ground-based radiative flux measurements analyzed in this study have been performed throughout the year 2012, at the Mathematics and Physics Department of the Università del Salento, Lecce (Italy) $\left(40.33^{\circ} \mathrm{N} ; 18.11^{\circ} \mathrm{E}\right)$, a coastal site of the Central Mediterranean area. Two Kipp \& Zonen pyranometers (CMP 21 model) and two Kipp \& Zonen pyrgeometers (CGR 3 model) have been used to retrieve upward and downward irradiance ( $\mathrm{F}_{\mathrm{UP}}$ and $\mathrm{F}_{\mathrm{DN}}$, respectively) at the surface in the SW $(0.31-2.8 \mu \mathrm{m})$ and in the LW (4.5-42 $\mu \mathrm{m})$ spectral range, respectively. Then, the CERES radiometers have allowed estimating directly $F_{U P}$ at the top of the atmosphere (TOA) and through an algorithm $F_{D N}$ and $F_{U P}$ at the surface in the SW $(0.3-5 \mu \mathrm{m})$ and in the LW (5$100 \mu \mathrm{m})$ spectral range, respectively.

\section{METHODOLOGY}

The Barcelona Supercomputing Center Dust REgional Atmospheric Model (BSC-DREAM8b v2.0, http://www.bsc.es) and the Ångstrom exponent $(\AA)$ calculated from the Aerosol Optical Depth (AOD) at 440 and $870 \mathrm{~nm}$ retrieved from AERONET (AErosol RObotic NETwork) sun/sky photometer measurements (http://aeronet.gsfc. nasa.gov) have been used to identify dusty days. In particular, we have considered as dusty days the ones characterized by a daily mineral dust loading greater than $0.05 \mathrm{~g} \mathrm{~m}^{-2}$ and a daily $\AA$ mean value lower than 0.9 , in accordance with BSC-DREAM8b and AERONET data, respectively. The true-color images from MODIS (MODerate resolution Image Spectroradiometer) on board AQUA and/or TERRA satellites (http://modis.gsfc.nasa.gov) and the analytical back-trajectories from the HYSPLIT (Hybrid Single Particle Lagrangian Integrated Trajectory) model (http://ready.arl.noaa.gov) have also been used to support BSC-DREAM8b and AERONET results. 
Clear-sky conditions have been defined for CERES footprints with cloud cover percentages less than 5\%, according to the method adopted in [2]. We have analyzed the SW and LW radiative fluxes at the surface and at the top of the atmosphere available in the Single Scanner Footprint (SSF) Level2 products of the CERES sensors (http://ceres.larc.nasa.gov). In particular, we have considered only CERES radiative flux values related to a field of view (FOV) center within an area of $0.5^{\circ}$ latitude by $0.5^{\circ}$ longitude around the study site.

\section{RESULTS}

Fig. 1 provides the monthly evolution of the AOD at $440 \mathrm{~nm}$ and the $\AA(440,870)$ mean values during the analyzed year 2012. The AOD monthly mean values ranged from 0.10 on December to 0.26 on August, while the $\AA$ monthly mean values varied from 1.82 on February to 0.77 on November. Then, Fig. 2 shows the absolute frequency of the clear-sky dusty and dust-free days, identified by using the previously described methodology, for each month of the studied year. No clear-sky dusty days were found in January, February, October, November, and December of the year 2012. The number of clear-sky dust-free days ranged from 4 on January and December to 23 on August, while the number of clear-sky dusty days varied from 3 on March to 6 on July. In particular, we have found 30 dusty days that represent the $19 \%$ of the total clear-sky days from March to September 2012. These results confirm that desert dust events are more frequent in spring/summer over the Mediterranean area. In fact, note that July was the month characterized by one of the largest (0.25) and lowest (1.27) monthly mean values of AOD and $\AA$, respectively, as reported in Fig. 1. Observe that a combination of large AOD with small $\AA$ may indicate a significant contribution of coarse mode mineral dust to the whole aerosol load. In addition, it is worth noting that the AOD mean value increased from 0.20 on dust-free days to 0.28 on dusty days, while the $\AA$ mean value decreased from 1.40 on dust-free days to 0.84 on dusty days during the period affected by the desert dust outbreaks (March-September 2012). Daytime mean values of clear-sky radiative fluxes have been divided into dust-free and dusty days mean values both in the SW and in the LW spectral domain, respectively, in order to quantify and investigate the monthly-based impact of mineral dust on the radiation measurements. Groundbased flux measurements have revealed that the monthly mean value of $\mathrm{SW}-\mathrm{F}_{\mathrm{DN}}$ decreased from $2.2 \%$ (April) to $4.2 \%$ (May) and the monthly mean value of $\mathrm{LW}-\mathrm{F}_{\mathrm{DN}}$ increased from $2.3 \%$ (May) to $6.1 \%$ (March) as a consequence of the mineral dust advection. In addition, the mean value of $\mathrm{SW}-\mathrm{F}_{\mathrm{DN}}$ decreased from $590 \mathrm{~W} \mathrm{~m}^{-2}$ on dust-free days to $570 \mathrm{~W} \mathrm{~m}^{-2}$ on dusty days, considering the period affected by the mineral dust intrusion (March-September 2012). Conversely, in the same period, the mean value of $L W-\mathrm{F}_{\mathrm{DN}}$ increased from $360 \mathrm{~W} \mathrm{~m}^{-2}$ on dust-free days to $370 \mathrm{~W} \mathrm{~m}^{-2}$ on dusty days. These flux changes were related to the previously reported variations of the analyzed aerosol properties (AOD and $\AA$ ).

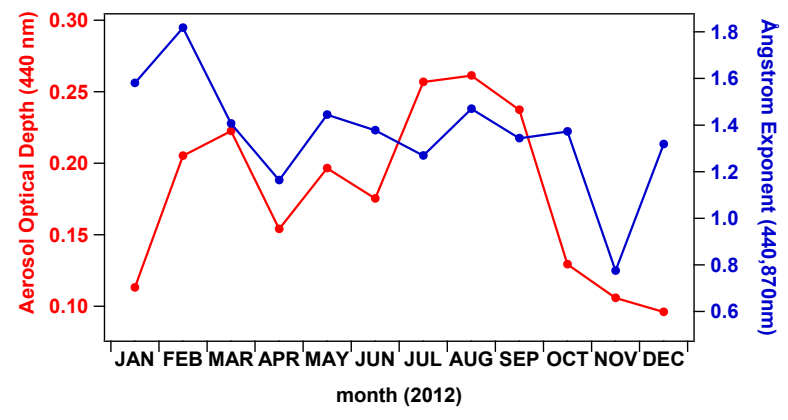

Fig. 1 Temporal evolution of the monthly mean values of the AOD at $440 \mathrm{~nm}$ (in red, on the left axis) and of the $\AA(440,870)$ (in blue, on the right axis) during the analyzed year 2012 .

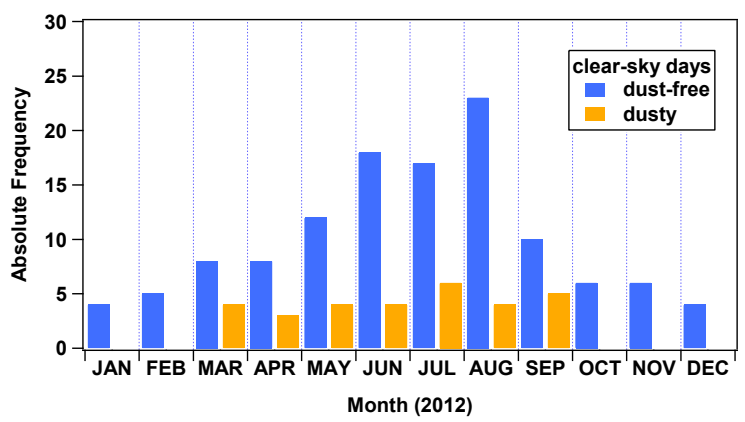

Fig. 2 Monthly-based absolute frequency of the clear-sky dust-free (in blue) and dusty (in orange) days during the analyzed year 2012 .

A moderate Saharan dust episode observed over south-eastern Italy from 9 to 13 July 2012 is analyzed in the following as a case study. Fig. 3 shows the temporal evolution of the AOD at 440 $\mathrm{nm}$ and of the $\AA(440,870)$ at the study site from 8 to 14 July 2012 . Note that July 10 and 12 were the 
days mostly affected by the desert dust advection during the analyzed period. In fact, the AOD, which was equal to 0.12 at midday of July 8 (dustfree day), reached the largest instantaneous values on July 10 and 12 ( 0.50 and 0.45 , respectively), according to Fig.3. In addition, the instantaneous $\AA$ values decreased from 1.65 at midday of July 8 to 0.56 and 0.54 at midday of July 10 and 12 , respectively. Then, the mineral dust loading that was equal to $0.02 \mathrm{~g} \mathrm{~m}^{-2}$ at 12:00 UTC of July 8 increased up to 0.12 and $0.15 \mathrm{~g} \mathrm{~m}^{-2}$ at 12:00 UTC of July 10 and 12, respectively, as a consequence of the Saharan dust advection, in accordance with the BSC-DREAM8b results. In particular, these AOD, $\AA$, and mineral dust loading changes have been responsible for a surface $\mathrm{SW}-\mathrm{F}_{\mathrm{DN}}\left(\mathrm{SW}-\mathrm{F}_{\mathrm{UP}}\right)$ decrease of 86 and $83 \mathrm{~W} \mathrm{~m}^{-2}$ (19 and $16 \mathrm{~W} \mathrm{~m}^{-2}$ ) on July 10 and 12, respectively. In the same time interval, the surface LW- $\mathrm{F}_{\mathrm{DN}}$ increased of 36 and $55 \mathrm{~W} \mathrm{~m}^{-2}$, while this effect was less evident for $\mathrm{LW}-\mathrm{F}_{\mathrm{UP}}$ (increase of 9 and $18 \mathrm{~W} \mathrm{~m}^{-2}$ ) since the latter is more affected by the ground properties. It is worth observing that the $\mathrm{F}_{\mathrm{UP}}$ evolution found at the top of the atmosphere is opposite to the one observed at the surface. The CERES-based TOA SW- $\mathrm{F}_{\mathrm{UP}}$ increased from $145 \mathrm{~W} \mathrm{~m}^{-2}$ at midday of July 8 to $238 \mathrm{~W} \mathrm{~m}^{-2}$ at midday of July 12 , as a consequence of the desert dust intrusion. On the contrary, the TOA LW-F $\mathrm{F}_{\mathrm{UP}}$ decreased from 327 to $309 \mathrm{~W} \mathrm{~m}^{-2}$ in the same time interval.

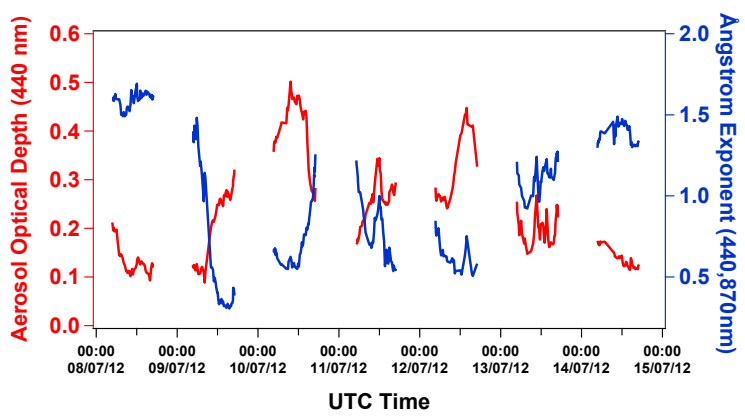

Fig. 3 Temporal evolution of the AOD at $440 \mathrm{~nm}$ (in red, on the left axis) and of the $\AA(440,870)$ (in blue, on the right axis) during the analyzed period of July 8-14, 2012.

During the analyzed dust outbreak, the clear-sky and satellite-derived surface $\mathrm{F}_{\mathrm{DN}}$ values have been compared with the collocated in time and space ground-based measurements in order to better support and understand the mineral dust radiative impact. Satellite-derived and ground-based $\mathrm{F}_{\mathrm{DN}}$ at the surface presented a high linear correlation coefficient $(0.87)$ in the SW spectral range. In a more detail, the SW-F $\mathrm{F}_{\mathrm{DN}}$ values measured at the surface on average slightly overestimated of $23 \mathrm{~W}$ $\mathrm{m}^{-2}(2.6 \%)$ the CERES-derived results during the studied period. This percentage difference resulted slightly greater than the total uncertainty related to the SW flux measurements (2\%). Yan et al. [2] also found ground-based $\mathrm{SW}-\mathrm{F}_{\mathrm{DN}}$ at the surface on average greater than corresponding CERESderived values during summer. A different relationship between satellite- and ground-based LW$F_{\mathrm{DN}}$ values at the surface was found for daytime and nighttime. A very low mean percentage difference $(1.5 \%)$ was observed for the nighttime period, resulting within the experimental error of $3 \%$. Conversely, all the LW- $\mathrm{F}_{\mathrm{DN}}$ values measured at the surface resulted larger than the related CERES-derived values for the daytime period, with a greater mean percentage difference $(6.8 \%)$, indicating the presence of a systematic error.

\section{CONCLUSIONS}

The mineral dust impact on ground- and satellitebased irradiance measurements both in the SW and in the LW range have been evaluated during the Saharan dust outbreaks that have affected south-eastern Italy throughout the year 2012. We have found that the mean value of the dusty days $\mathrm{SW}-\mathrm{F}_{\mathrm{DN}}$ at the surface was $20 \mathrm{~W} \mathrm{~m}^{-2}$ smaller than the dust-free days one from March to September 2012, which was the period affected by the desert dust intrusions. Conversely, in the same period, the mean value of the dusty days $\mathrm{LW}-\mathrm{F}_{\mathrm{DN}}$ at the surface was $10 \mathrm{~W} \mathrm{~m}^{-2}$ greater than the dust-free days one. In addition, we have found that the surface SW- and LW- $\mathrm{F}_{\mathrm{DN}}$ decreased up to $9 \%$ and increased up to $13 \%$, respectively, compared to a pristine dust-free day during the studied mineral dust outbreak of July 9-13, 2012. These outcomes are due to the cooling and warming effect by mineral dust at the surface in the SW and LW spectral range, respectively. On the contrary, we have found that the mineral dust advection was responsible for an increase and a decrease of the $F_{U P}$ at the top of the atmosphere in the SW and in the LW spectral range, respectively. Finally, we have observed that the ground-based $\mathrm{SW}-\mathrm{F}_{\mathrm{DN}}$ was on average $2.6 \%$ greater than the corresponding ones retrieved from CERES radiometer sensors resulting within the experimental uncertainty. The mean percentage difference between ground- and satellite-based LW-F $\mathrm{F}_{\mathrm{DN}}$ at the surface, which was 
equal to $1.5 \%$ on nighttime and $6.8 \%$ on daytime, resulted within and without the experimental error, respectively.

\section{ACKNOWLEDGEMENT}

S. Romano has carried out this work with support of a $\mathrm{PhD}$ fellowship from the Mathematics and Physics Department of the Università del Salento. This study has been supported by the European Community through the ACTRIS Research Infrastructure Action under the 7th Framework Programme, ACTRIS grant agreement no. 262254. The authors gratefully acknowledge the NASA/ Goddard Space Flight Center for the provision of CERES data and satellite images. The NOAA Air Resources Laboratory (ARL) and the Barcelona Super-Computing Centre are also acknowledged for their contribution of HYSPLIT and DREAM model results, respectively.

\section{REFERENCES}

[1] Lelieveld, J., H. Berresheim, S. Bormann, P.J. Crutzen, F.J. Dentener and coauthors, 2002: Global air pollution crossroads over the Mediterranean, Science, 298, 794-799.

[2] Yan, H., J. Huang, P. Minnis, T. Wang, J. Bi, 2011: Comparison of CERES surface radiation fluxes with surface observations over Loess Plateau, Remote Sens. Environ., 115, 1489-1500. 